\title{
Expression of inositol-requiring enzyme $1 \beta$ is downregulated in colorectal cancer
}

\author{
YALIN JIANG $^{1,2^{*}}$, YUNFENG ZHOU ${ }^{3 *}$, YUFENG ZHENG $^{1}$, HONG GUO $^{1}$, LEI GAO $^{1}$, PAN CHEN $^{1}$, \\ DANDAN FENG $^{1}$, RAN QI ${ }^{1}$, XIAOZHEN LI ${ }^{1}$, YONGCHAO CHANG ${ }^{2}$, FONG-FONG CHU ${ }^{1}$ and QIANG GAO ${ }^{1}$ \\ Departments of ${ }^{1}$ Gastroenterology and Hepatology and ${ }^{2}$ Clinical Laboratory, \\ The First Affiliated Hospital and College of Clinical Medicine, Henan University of Science and Technology, Luoyang, \\ Henan 471023; ${ }^{3}$ Shenzhen University Health Science Center, Shenzhen, Guangdong 518060, P.R. China
}

Received July 31, 2015; Accepted September 12, 2016

DOI: $10.3892 / \mathrm{ol} .2017 .5590$

\begin{abstract}
The endoplasmic reticulum stress inositol-requiring enzyme (IRE) 1 $\alpha / \mathrm{X}$-box binding protein (XBP) 1 signaling pathway is involved in the tumorigenesis of breast and prostate cancer. Mucin 2 (MUC2) protects colon tissues from the formation of tumors. In human colorectal cancer (CRC) the role of IRE1 $\alpha$, and its analogue, IRE1 $\beta$, has yet to be elucidated. In the present study, the expression levels of IRE1 $\alpha$, IRE1 $\beta$, un-spliced XBP1u, spliced XBP1s and MUC2 in surgically resected cancerous and adjacent non-cancerous tissues from patients with CRC were investigated. The IRE1 $\alpha$, IRE1 $\beta$, XBP1u, XBP1s and MUC2 mRNA expression levels were determined using reverse transcription-quantitative polymerase chain reaction, and the protein expression levels were detected using immunohistochemistry and western blotting. The association between the expression levels of IRE1 $\alpha$, IRE1 $\beta$ and MUC2 and the clinicopathological features of patients with CRC was subsequently analyzed. The mRNA expression levels of IRE1 $\beta$ and MUC2 were decreased by $~ 2.1$ and $~ 4.5$-fold in CRC tissues, respectively, as compared with the adjacent normal tissues. The protein expression levels of IRE1 $\beta$ and MUC2 were decreased by $\sim 8.0$ and $\sim 2.0$-fold in
\end{abstract}

Correspondence to: Dr Qiang Gao, Department of Gastroenterology and Hepatology, The First Affiliated Hospital and College of Clinical Medicine, Henan University of Science and Technology, 636 Guanlin Road, Luoyang, Henan 471023, P.R. China E-mail: gaoq@mail.haust.edu.cn

\section{${ }^{*}$ Contributed equally}

Abbreviations: ATF6, activating transcription factor 6; CRC, colorectal cancer; ER, endoplasmic reticulum; IRE1, inositol-requiring enzyme 1; MUC, mucin; PERK, protein-kinase-RNA-like-ER kinase; RIDD, regulated IRE1-dependent decay; UPR, unfolded protein response; XBP1, $\mathrm{X}$-box binding protein 1

Key words: colorectal cancer, endoplasmic reticulum stress, inositol-requiring enzyme 1 , mucin $2, \mathrm{X}$-box binding protein 1 the CRC tissues, respectively. IRE1 $\beta$ mRNA expression levels were positively correlated with MUC2 mRNA expression levels. IRE1 $\beta$ expression levels were revealed to be significantly associated with lymph node metastasis, tumor stage and histological differentiation. However, IRE1 $\alpha, \mathrm{XBP} 1 \mathrm{u}$ and XBP1s mRNA and IRE1 $\alpha$ protein expression levels were not observed to significantly differ between cancerous tissues and the adjacent normal tissues. The results indicated that the expression of IRE1 $\beta$, but not IRE1 $\alpha$, may protect colon tissue from developing CRC by inducing MUC2 expression. Therefore, decreased IRE1 $\beta$ expression levels may be associated with the development of CRC through the inhibition of MUC2 expression.

\section{Introduction}

Colorectal cancer (CRC) is the third most commonly diagnosed cancer and the second leading cause of cancer-associated mortality in the United States (1). In China, CRC is the fifth leading cause of cancer-associated mortality, following lung, liver, gastric and esophageal cancer (2). The incidence of CRC in China has increased in recent decades and is predicted to continue rising due to changes in lifestyle and diet $(3,4)$. Although novel treatments have been developed, the five-year survival rate of patients with CRC and distant metastases remains poor at $\sim 13 \%$ (5-7). CRC develops from the accumulation of genetic and epigenetic alterations, leading to gene amplifications, the activation of certain oncogenes or the loss of tumor suppressor genes (6).

Previous studies have demonstrated that the activation of endoplasmic reticulum (ER) stress in cancer cells may facilitate their survival and tumor growth; however, certain studies have revealed that ER stress may inhibit cancer progression $(8,9)$. During ER stress, various pathological changes occur to induce ER calcium depletion and the accumulation of misfolded proteins in the ER lumen (10). Mammalian cells have three classes of ER stress sensors, including protein-kinase-RNA-like-ER kinase (PERK), activating transcription factor 6 (ATF6) and inositol-requiring enzyme-1 $\alpha$ (IRE1 $\alpha)(10-12)$. These sensors are resident ER transmembrane proteins, which regulate the unfolded protein response (UPR) to manage ER stress (11). The UPR includes 
the alteration of protein folding, assembly and degradation programs in order to reestablish homeostasis and normal ER functioning $(11,13)$.

IRE1 $\alpha$ has a dual enzyme activity, as it is a kinase and a site-specific RNA endonuclease $(8,14)$. IRE1 $\alpha$ is frequently mutated in various types of human cancer (15). One manner in which IRE1 $\alpha$ maintains ER homeostasis is by processing the mRNA encoding X-box binding protein 1 (XBP1) (16). IRE1 $\alpha$ activates XBP1 protein expression by excising a 26-nucleotide-intron sequence from the un-spliced XBP1 mRNA (XBP1u) and creating the spliced XBP1 mRNA (XBP1s). The subsequent frame shift mutation eliminates a stop codon for protein translation $(17,18)$. XBP1 is a transcription factor that is involved in tumor growth and survival $(9,17)$. XBP1 expression levels are increased in numerous types of cancer, including breast cancer (19), hepatocellular carcinoma (20), pancreatic cancer (17), and CRC, as determined in a study of five patients (21); however, XBP1 expression levels may be decreased in prostate cancer (22). IRE1 $\alpha$ may also induce UPR through the post-transcriptional modifications of specific ER membrane proteins via regulated IRE1-dependent decay (RIDD) (8). RIDD is the process by which IRE1 $\alpha$ promotes the degradation of mRNAs primarily encoding ER-targeted proteins, in order to reduce the influx of proteins during ER stress $(23,24)$. In the present study, IRE1 $\alpha$ and XBP1 mRNA expression levels in CRC tissues were analyzed to determine whether they are increased, compared with the paired control samples.

IRE1 $\beta$ is an analog of IRE1 $\alpha$ (25). Whereas IRE1 $\alpha$ is expressed ubiquitously, the expression of IRE1 $\beta$ is restricted to the epithelium of the gastrointestinal and respiratory tracts $(26,27)$. Although previous studies have demonstrated that IRE $1 \alpha$ and IRE1 $\beta$ are each able to sense ER stress and protect mice from dextran sulfate sodium-induced colitis $(26,28)$, they have differing functions. The two IRE1 proteins have various substrate specificities; the RNase activity of IRE1 $\alpha$ with regard to XBP1u mRNA is markedly high, compared with IRE1 $\beta$ (27). IRE1 $\alpha$ directs cell survival through the induction of XBP1 mRNA cleavage and the promotion of RIDD (28). IRE1 $\alpha$ signaling terminates in the event of cell apoptosis induced by irremediable ER stress (29-31). IRE1 $\beta$ is more efficient than IRE1 $\alpha$ at degrading 28 s rRNA (16). The cleavage of 28s rRNA may induce apoptosis, as previously demonstrated in IRE1 $\beta$-overexpressing HeLa cells (32). The RNase activity of IRE1 $\beta$ appears to have broad substrate specificity; it regulates the stability of the mRNA that encodes certain ER proteins and maintains ER homeostasis in highly differentiated secretory cells (16). Thus, IRE1 $\beta$, but not IRE1 $\alpha$, degrades the mRNA encoding specific secretory proteins, including mucin 2 (MUC2) in the intestinal goblet cells $(16,33)$. MUC2 is a macromolecular glycoprotein secreted by goblet cells (34). MUC2 is crucial to host immune system and protects colon tissues from developing colitis or CRC; MUC2-deficient mice have been observed to develop spontaneous colitis and colon cancer (35-38). The differences between the substrates of IRE1 $\alpha$ and IRE1 $\beta$ suggest their divergent functions in ER stress, and may also reflect their various roles in the tumorigenesis of CRC (29). Therefore, IRE1 $\beta$ and MUC2 gene expression profiles in CRC tissue samples were analyzed in the current study.
In the present study, the expression levels of the signaling pathways IRE1 $\alpha$-XBP1, IRE1 $\beta$ and MUC2 in colon cancer tissues were investigated by reverse transcription-quantitative polymerase chain reaction (RT-qPCR), western blotting and immunohistochemistry, and their associations with the clinical features of CRC patients were explored. This study may identify potential important targets for cancer therapies.

\section{Materials and methods}

Patients and tissue samples. The CRC tissue samples were obtained from surgically resected tumor tissues from patients with colorectal adenocarcinoma at the First Affiliated Hospital of Henan University of Science and Technology, between September 1st, 2013 and February 31st, 2014. The clinicopathological features of the patients recruited for the current study are listed in Table I. Tumor tissues and adjacent non-cancerous tissues (serving as controls) were analyzed. The control non-cancerous tissues were taken from an area $\sim 5 \mathrm{~cm}$ from the lesion. Patients with colorectal adenocarcinoma were selected, while those patients with mucinous, signet-ring cell carcinoma, squamous carcinoma, adenosquamous carcinoma or undifferentiated carcinoma forms of CRC were excluded. Mucinous CRC was excluded due to its high level of MUC2 expression compared with that in normal colon tissues $(36,39,40)$.

Two staff pathologists confirmed the diagnosis of CRC. A section of each tissue sample was fixed in $4 \%$ paraformaldehyde and embedded in paraffin wax for hematoxylin and eosin staining and immunohistochemistry (IHC). The remaining section of the tissue sample was stored at $-80^{\circ} \mathrm{C}$ for RNA extraction and western blot analysis. RNAlater (Qiagen $\mathrm{GmbH}$, Hilden, Germany; cat. no. 76106) was added immediately following the tissue sample collection in order to prevent RNA degradation. The tumor stages were classified according to the 7th edition of the tumor-node-metastasis (TNM) classification criteria of the American Joint Committee on Cancer (41). Informed consent was obtained from all patients and the Clinical Research Ethics Committee of The First Affiliated Hospital of Henan University of Science and Technology approved the current study.

$R T-q P C R$. Total RNA was extracted using TRIzol ${ }^{\circledR}$ Reagent (Invitrogen; Thermo Fisher Scientific, Inc., Waltham, MA, USA) according to the manufacturer's instructions. A total of $2 \mu \mathrm{g}$ total RNA was used for cDNA synthesis using PrimeScript $^{\mathrm{TM}}$ RT Master Mix (Takara Bio, Inc., Otsu, Japan) in a $40 \mu 1$ reaction mixture (8 $\mu 1$ 5X RT Master Mix; total RNA; diethylpyrocarbonate), as follows: $37^{\circ} \mathrm{C}$ for $15 \mathrm{~min}, 85^{\circ} \mathrm{C}$ for $5 \mathrm{sec}$ and $4^{\circ} \mathrm{C}$ for $10 \mathrm{~min}$. The primer sequences for IRE1 $\alpha$, XBP1u, XBP1s, IRE1 $\beta$, MUC2 and $\beta$-actin were designed using Primer3.0 software (42) and synthesized by Sangon Biotech Co., Ltd. (Shanghai, China; Table II). RT-qPCR was conducted using a CFX96 ${ }^{\mathrm{TM}}$ Real-Time PCR system (Bio-Rad Laboratories, Inc., Hercules, CA, USA). The reaction mixture (25 $\mu \mathrm{l}$ total volume per well) included $2 \mu \mathrm{l}$ cDNA, $12.5 \mu \mathrm{l}$ 2xSYBR Premix Ex Taq II (Takara Bio, Inc.), $8.5 \mu 1 \mathrm{H}_{2} \mathrm{O}$ and $2 \mu \mathrm{l} 0.4 \mu \mathrm{M}$ primers. A two-step method was used due to the $60^{\circ} \mathrm{C}$ annealing temperature. The reaction consisted of the following: $95^{\circ} \mathrm{C}$ for $30 \mathrm{sec}, 40$ cycles of $95^{\circ} \mathrm{C}$ for $5 \mathrm{sec}$ and 
$60^{\circ} \mathrm{C}$ for $30 \mathrm{sec}$. Each tissue sample was assayed in triplicate. The efficiency of the PCR amplification process was $97-105 \%$. A melting curve analysis was performed for the PCR products of the target genes in order to evaluate primer specificity. Relative quantification of the target gene mRNA expression was conducted using quantification cycle $(\mathrm{Cq})$ with the formula $\log _{10} 2^{-\Delta \Delta \mathrm{Cq}}(43)$ and normalized to $\beta$-actin. The difference in mRNA expression was presented as the relative fold between the groups. A Cq value of $>35$ was considered to indicate that a specific gene was not expressed.

Immunohistological staining for IRE1 $\alpha$, IRE1 $\beta$ and MUC2. Sections $(4 \mu \mathrm{m})$ of paraffin-embedded tissue samples were mounted on poly-L-lysine-coated slides. IHC was performed using an indirect peroxidase-labelled antibody method as previously described (44). Briefly, the tissue sections were dewaxed in xylene, rehydrated with graded alcohol and antigen retrieval was conducted by microwave-boiling the slides for $10 \mathrm{~min}$ in $0.01 \mathrm{~mol} / 1$ sodium citrate buffer, $\mathrm{pH}$ 6.0. Endogenous peroxidase was blocked by incubation in $3 \%$ hydrogen peroxide for $10 \mathrm{~min}$. Following washing in distilled water, non-specific binding was blocked by $5 \%$ bovine serum albumin (Sigma-Aldrich: Merck Millipore, Darmstadt, Germany) for $20 \mathrm{~min}$ at $37^{\circ} \mathrm{C}$. The tissue sections were then incubated overnight at $4^{\circ} \mathrm{C}$ with rabbit polyclonal antibodies against IRE1 $\alpha$ (Abcam, Cambridge, UK; dilution, 1:200; cat. no. ab37073) and IRE1 $\beta$ (Abcam; dilution 1:50; cat. no. ab135795), and an anti-MUC2 mouse monoclonal antibody (Abcam; dilution, 1:500; cat. no. ab11197). The antigen-antibody complex was then detected with a biotinylated goat anti-rabbit antibody (Boster Biological Technology Co., Ltd., Wuhan, China; cat. no. BA1101) and an anti-mouse antibody (Boster Biological Technology Co., Ltd.; cat. no. SA1020), subsequently conjugated with streptoavidin-horseradish peroxidase (HRP) (Boster Biological Technology Co., Ltd.; cat. no. SA1022) and visualized by reacting with nickel-enhanced 3,3-diaminobenzidine tetrahydrochloride (Solarbio Science and Technology Co., Ltd.; cat. no. D8230) for color detection. The tissue sections were then counterstained with hematoxylin. The negative control sections were obtained by omitting the primary antibody or by using an unrelated rabbit polyclonal antibody.

The antigen levels in the IHC stained tissue samples were evaluated in 10 random fields (400x magnification) for each section. A total of 100 cells/field were categorized as follows: 0, 0-5 cells were stained; 1, 6-25 cells were stained; 2 , 26-50 cells stained; $3,51-75$ cells stained; and 4, 76-100 cells stained. In addition, the staining intensity was scored as follows: 0 , no staining; 1 , weak staining; 2 , moderate staining; 3 , intense staining. The intensity score was multiplied by the frequency score, in order to obtain the final score. A final score of $\geq 6$ indicated high expression levels, whereas a score of $<6$ indicated low expression levels (45).

Western blotting analysis of IRE1 $\beta$. Protein lysates were prepared from collected tissue samples in radioimmunoprecipitation assay lysis buffer (Solarbio Science and Technology Co., Ltd.) on ice by homogenization with a grinder. The supernatant was obtained following centrifugation at $10,800 \mathrm{x} g$ for $15 \mathrm{~min}$ at $4^{\circ} \mathrm{C}$. A bicinchoninic acid assay (Solarbio Science and Technology Co., Ltd., ) method was used to determine the protein concentrations. Protein $(30 \mu \mathrm{g})$ from each tissue sample was denatured and resolved by $10 \%$ sodium dodecyl sulfate polyacrylamide gel electrophoresis, and then transferred onto polyvinylidene difluoride membranes (EMD Millipore, Billerica, MA, USA). Following blocking for $1 \mathrm{~h}$ at $37^{\circ} \mathrm{C}$ in $5 \%$ skim milk, the membranes were incubated with the anti-IRE1 $\beta$ antibody (Abcam; dilution 1:200; cat. no. ab135795) for $3 \mathrm{~h}$ at $37^{\circ} \mathrm{C}$, then washed four times in $1 \mathrm{X}$ TBST. The membranes were subsequently incubated with HRP-conjugated anti-IgG secondary antibody (Boster Biological Technology Co., Ltd.; dilution, 1:1,000; cat. no. BA1054) and then washed four times in $1 \mathrm{X}$ TBST. The proteins were visualized using an enhanced chemiluminescence reagent (Pierce; Thermo Fisher Scientific, Inc.) according to the manufacturer's protocol. An anti- $\beta$-actin mouse monoclonal antibody (Abcam; dilution, 1:3,000; cat. no. ab8226) was used to normalize for the protein loading. The secondary antibody for $\beta$-actin was a HRP-conjugated goat anti-mouse IgG (Boster Biological Technology Co., Ltd.; dilution, 1:1,000; cat. no. BA1050). ChemiDoc XRS (Bio-Rad Laboratories, Inc.) was used to capture the images, and the intensity of the images was quantified using ImageJ software v1.48 (National Institutes of Health, Bethesda, MD, USA).

Statistical analysis. A Student's $t$-test and a Mann-Whitney U-test were used to determined significant differences between the groups. A Wilcoxon signed-rank test was used for non-parametric data. Spearman's bivariate analysis was used to determine the correlation between IRE1 $\beta$ and MUC2 mRNA expression levels. The data are presented as the mean \pm standard deviation. All statistical analysis was performed using using the SPSS 19.0 statistical package (SPSS Inc., Chicago, IL, USA). $\mathrm{P}<0.05$ was considered to indicate a statistically significant result.

\section{Results}

Clinical characteristics. A total of 42 patients were recruited for the current study and the clinical features are summarized in Table I. The ages of the patients ranged from 44-82 years (average, 61.3 years). A total of 18 patients were male and 24 were female. The discrepancy in gender ratio of this study from the China colorectal report may be due to the gender ratio in the local area $(4,46)$.

Expression levels of IRE $1 \alpha, X B P 1, I R E 1 \beta$ and $M U C 2$ $m R N A$ in $C R C$ tissues. XBP1 expression levels are increased in numerous types of cancer, including CRC $(8,17,18)$. During UPR, IRE1 $\alpha$ initiates the splicing of XBP1u mRNA to XBP1s, generating an XBP1 transcription factor that regulates a subset of UPR genes to constitute the IRE1 $\alpha$-XBP1 signaling pathway $(8,16)$. RT-qPCR was used to analyze the mRNA expression levels of IRE1 $\alpha$, XBP1u and XBP1s in tissue samples from patients with CRC. The paired colon tissue samples were analyzed in 31 patients for IRE1 $\alpha$ mRNA and 12 patients for XBP1u and XBP1 s mRNAs. It was identified that IRE1 $\alpha, \mathrm{XBP} 1 \mathrm{u}$ and XBP1s mRNAs were expressed at similar levels in the CRC and non-cancerous tissues (Fig. 1A and Table III).

IRE1 $\beta$, an analog of IRE1 $\alpha$, is specifically expressed in the epithelium of the gastrointestinal and respiratory tracts; 
Table I. Clinicopathological characteristics of the included patients with colorectal carcinoma $(n=42)$.

\begin{tabular}{lc} 
Variable & Number of cases (\%) \\
\hline Gender & $18(42.9)$ \\
Male & $24(57.1)$ \\
Female & \\
Age (years) & $18(42.9)$ \\
$<60$ & $24(57.1)$ \\
$\geq 60$ & \\
Tumor size (cm) & $11(26.2)$ \\
$<5$ & $28(66.7)$ \\
$\geq 5$ & $3(7.1)$ \\
Data incomplete & \\
Differentiation & $11(26.2)$ \\
WMDC & $27(77.1)$ \\
MDC & $4(9.5)$ \\
PMDC & \\
Lymphatic node metastasis & $15(35.7)$ \\
Negative & $27(64.3)$ \\
Positive & \\
TNM stage & $24(57.1)$ \\
I-II & $18(42.9)$ \\
III-IV &
\end{tabular}

WMDC, well-moderately differentiated carcinoma; MDC, moderately differentiated carcinoma; PMDC, poor-moderately differentiated carcinoma; TNM, tumor node metastasis.

MUC2 expression in the intestine is regulated by IRE1 $\beta$, but not by IRE1 $\alpha(27,47)$. IRE1 $\beta$ and MUC2 mRNA expression levels were evaluated in 35 patients with CRC. The mRNA expression levels of IRE1 $\beta$ and MUC2 in the cancerous tissues were 2.1 and 4.5 -fold lower, respectively, compared with in the adjacent non-cancerous colon mucosa (Fig. 1B and 1C). It was identified that MUC2 mRNA expression levels were positively correlated with IRE1 $\beta$ mRNA expression levels $(r=0.45$; $\mathrm{P}=0.01$; Fig. 1D).

mRNA expression levels of IRE1 $\beta$, but not IRE1 $\alpha$ or MUC2, were associated with lower clinical stages, metastasis and poor differentiation in $C R C$. To evaluate the clinical significance of changes in the mRNA expression levels of IRE1 $\beta$, IRE1 $\alpha$ and MUC2 in CRC tissues, the association between the mRNA expression levels of these genes and the clinicopathological features of the patients with CRC, were analyzed. It was identified that IRE1 $\beta$ mRNA expression levels were significantly associated with tumor differentiation $(\mathrm{P}=0.049)$, lymph node metastasis $(\mathrm{P}=0.043)$ and TNM stage $(\mathrm{P}=0.018)$ (Table IV), but not with gender $(\mathrm{P}=0.709)$, age $(\mathrm{P}=0.558)$ and $\mathrm{T}$-stage classification $(\mathrm{P}=0.384)(48,49)$ (data not presented). Although the mRNA expression levels of IRE1 $\beta$ in the tumor tissues were low compared with the adjacent normal tissues, in poor-moderately differentiated CRC tissues the IRE1 $\beta$ mRNA expression levels were high as compared with in well-differentiated CRC tissues. Furthermore, those patients with lymphatic metastasis or stage III-IV CRC, had high IRE1 $\beta$ mRNA expression levels, as compared with those patients without lymphatic metastasis or stage I-II CRC. IRE1 $\alpha$ and MUC2 mRNA expression levels were not observed to be significantly associated with patient clinicopathological features (Table IV).

Immunohistochemistry of IREI $\alpha$, IRE1 $\beta$ and MUC2 in CRC tissues. ER stress is emerging as an important factor in tumor pathogenesis $(8,9)$. However, to the best of our knowledge, there are no previous reports on the role of IRE1 $\alpha$ in the tumorigenesis of CRC. Although it was demonstrated in the current study that the mRNA expression levels of IRE1 $\alpha$ are similar in CRC and adjacent normal tissues, as IRE1 $\alpha$ regulates ER stress at the protein level, the IRE1 $\alpha$ protein expression levels were also evaluated using IHC (Fig. 2A and B). IRE1 $\alpha$ was expressed in the plasma membrane of non-cancerous colon epithelium and IRE1 $\alpha$ was stained at apical surface of cancerous epithelial cells in the colon. In submucosa, certain unidentified cells also had positive nuclei staining for IREl $\alpha$. Again, there was no significant difference in IRE1 $\alpha$ protein expression levels between CRC and non-cancerous tissue (Fig. 2C).

Aberrant mucin accumulation in the goblet cells of mouse colons was observed when the IRE1 $\beta$ gene was deleted (33), and IRE1 $\beta$ was revealed to be required for airway mucin excretion (27). In the current study, it was also identified that the IRE1 $\beta$ protein was expressed in colon epithelial cells, including in goblet cells. However, by contrast with a prior animal study (33), the results did not demonstrate a predominant IRE1 $\beta$-positive staining in human colon goblet cells. Above the nuclei of the epithelial cells, a strong positive staining was observed in non-cancerous tissue samples (Fig. 2D). In the cytoplasm of CRC tissues, IRE1 $\beta$ positive staining was comparatively low (Fig. 2E and F); in normal and cancerous tissues, there were unidentified cells that were weakly stained in the submucosa. Similar to the mRNA expression of IRE1 $\beta$, the downregulation of IRE1 $\beta$ was significantly associated with tumor differentiation $(\mathrm{P}=0.047)$, lymph node metastasis $(\mathrm{P}=0.009)$ and TNM stage $(\mathrm{P}=0.001)$ (Table V). No significant association was identified between IRE1 $\beta$ expression levels and other clinicopathological factors, including gender $(\mathrm{P}=0.998)$, age $(\mathrm{P}=0.115)$ and tumor size $(\mathrm{P}=0.742)$ (data not presented).

MUC2 protein is present in the goblet cells of the colon epithelium $(34,50)$. It has been reported that the IHC staining of MUC2 in goblet cells exhibits whole-cell filled or peri-nuclear staining patterns $(51,52)$. In the present study, the MUC2 staining pattern was half-filled in the goblet cells, and MUC2 expression levels were significantly decreased in these CRC tissues $(\mathrm{P}<0.001$; Fig. 2G-I). Similar to MUC2 mRNA expression levels, the MUC2 protein expression levels, as quantified by IHC staining, were not significantly associated with the clinicopathological factors of patients with CRC (data not presented).

Western blot analysis of IREI $\beta$ expression in CRC tissues. The protein expression levels of IRE1 $\beta$ in 13 paired CRC and adjacent normal tissue samples were evaluated using western blotting. Similar to the expression levels of IRE1 $\beta$ in the mRNA and IHC results, a significant difference was identified 
Table II. Primers sequences for reverse transcription-quantitative polymerase chain reaction.

\begin{tabular}{lllc}
\hline mRNA & Gene & \multicolumn{1}{c}{ Primer sequence (5'-3') } & Amplicon (bp) \\
\hline NM-001433 & IRE1 $\alpha$ & $\begin{array}{l}\text { Forward CTCCGAGCCATGAGAAATAAG } \\
\text { Reverse GGGAAGCGAGATGTGAAGTAG } \\
\text { Forward AAGTGGTAGATTTAGAAGAAGAGAA }\end{array}$ & 113 \\
NM-001079539 & XBP1s & $\begin{array}{l}\text { Reverse ACCTGCTGCGGACTCAG } \\
\text { Forward AGTCCGCAGCACTCAG }\end{array}$ & 200 \\
NM-005080 & XBP1u & Reverse GGGTCCAAGTTGTCCAGA & 150 \\
NM-033266 & IRE1 $\beta$ & Forward TCCCCTTATAGGACCGGAAC & 147 \\
NM-002457 & MUC2 & $\begin{array}{l}\text { Forward GACACCATCTACCTCACCCG } \\
\text { Reverse TGTAGGCATCGCTCTTCTCA }\end{array}$ & 103 \\
NM-00110 & $\beta$-actin & $\begin{array}{l}\text { Forward AGCACTGTGTTGGCGTACAG } \\
\text { Reverse CTCTTCCAGCCTTCCTTCCT }\end{array}$ & 116 \\
\end{tabular}

IRE1, inositol-requiring enzyme 1; MUC2, mucin 2; XBP1, X-box binding protein 1; s, spliced; u, unspliced; bp, base pairs.
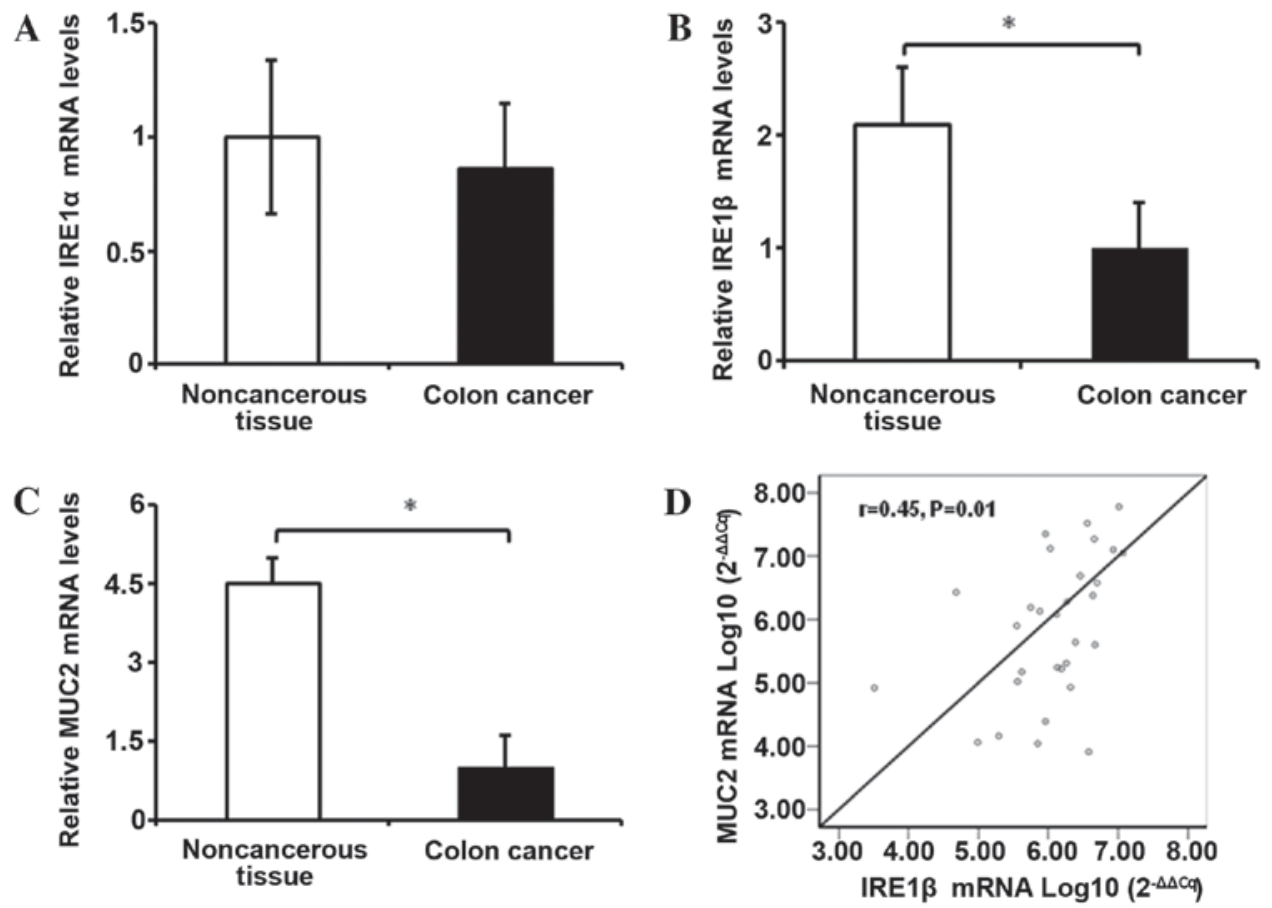

Figure 1. IRE1 $\alpha$, IRE1 $\beta$ and MUC2 mRNA expression in CRC tissues. (A) The mRNA expression levels of IRE1 $\alpha$ in cancerous tissues were similar to those in paired noncancerous tissues $(n=31)$. (B and C) IRE1 $\beta$ and MUC2 mRNA expression levels were decreased in CRC tissues, compared with paired non-cancerous tissues ( $\mathrm{n}=35$ ), and (D) MUC2 mRNA expression levels were positively associated with IRE1 $\beta$ mRNA expression levels. The data are presented as the mean \pm standard deviation. ${ }^{*} \mathrm{P}<0.05$, vs. the non-cancerous tissues. IRE1, inositol-requiring enzyme 1; MUC2, mucin 2; CRC, colorectal cancer.

in the IRE1 $\beta$ protein expression levels, which were 8-fold lower in cancerous tissues, compared with the adjacent normal control tissues (Fig. 3A and B; $\mathrm{P}<0.001$ ), which indicated that the expression level was decreased in CRC tissues at the transcriptional and translational levels.

\section{Discussion}

ER stress affects tumorigenesis and elevation of the XBP1 transcription factor has previously been reported in numerous types of cancer, including CRC $(9,19,21)$. As XBP1 mRNA is processed by IRE1 $\alpha$, the IRE1 $\alpha$, XBP1u and XBP1s mRNA expression levels, and IRE1 $\alpha$ protein expression levels, were analysed in cancerous and adjacent normal colon tissue samples; however, no significant difference was observed between the two tissues. Although Fujimoto et al (21) identified that XBP1 gene and protein expression levels were increased in 4/5 CRC tissues, the sample size in their study was small. In the current study, XBP1u and XBP1s gene expression levels were analyzed in 12 cases of CRC. Additionally, the IRE1 $\alpha$ mRNA and protein expression levels were evaluated and no significant changes were observed in CRC 
Table III. XBP1u and XBP1s mRNA expression levels in patients with colorectal cancer.

\begin{tabular}{|c|c|c|c|c|c|c|}
\hline \multirow[b]{2}{*}{ No. } & \multirow[b]{2}{*}{ Patient } & \multirow[b]{2}{*}{ Gender } & \multirow[b]{2}{*}{ Age (years) } & \multirow[b]{2}{*}{ Differentiation } & \multicolumn{2}{|c|}{ Ratio $(\mathrm{C} / \mathrm{N})$} \\
\hline & & & & & XBP1u & XBP1s \\
\hline 1 & C58 & $\mathrm{m}$ & 44 & PDC & 2.5 & 0.8 \\
\hline 2 & C57 & $\mathrm{f}$ & 65 & MDC & 1.0 & 1.0 \\
\hline 3 & $\mathrm{C} 24$ & $\mathrm{f}$ & 53 & MDC & 0.8 & 0.8 \\
\hline 4 & $\mathrm{C} 29$ & $\mathrm{~m}$ & 64 & MDC & 1.1 & 1.0 \\
\hline 5 & C31 & $\mathrm{m}$ & 61 & MDC & 0.9 & 0.8 \\
\hline 6 & C33 & $\mathrm{m}$ & 61 & MDC & 2.0 & 2.5 \\
\hline 7 & C52 & $\mathrm{f}$ & 61 & MDC & 1.1 & 0.8 \\
\hline 8 & C53 & $\mathrm{f}$ & 60 & MDC & 0.5 & 0.4 \\
\hline 9 & C54 & f & 52 & WMDC & 1.4 & 2.5 \\
\hline 10 & C55 & $\mathrm{f}$ & 68 & WDC & 1.1 & 1.3 \\
\hline 11 & C56 & $\mathrm{f}$ & 47 & WDC & 5.0 & 5.0 \\
\hline 12 & C59 & $\mathrm{f}$ & 47 & WDC & 1.0 & 1.4 \\
\hline $\begin{array}{l}\text { Mean } \pm \text { standard } \\
\text { deviation }\end{array}$ & & & & & $1.1 \pm 0.5$ & $1.0 \pm 0.6$ \\
\hline
\end{tabular}

XBP1, X-box binding protein 1; s, spliced; u, unspliced; f, female; m, male; PDC, poorly differentiated carcinoma; MDC, moderately differentiated carcinoma; WMDC, well-moderately differentiated carcinoma; WDC, well-differentiated carcinoma; C/N, cancerous tissue/ noncancerous tissue.

Table IV. IRE1 $\alpha$, IRE1 $\beta$ and MUC2 mRNA expression levels in patients with CRC.

\begin{tabular}{|c|c|c|c|c|c|c|c|c|c|}
\hline \multirow[b]{2}{*}{ Variables } & \multicolumn{3}{|c|}{ IRE1 $\alpha$ mRNA } & \multicolumn{3}{|c|}{ IRE1 $\beta$ mRNA } & \multicolumn{3}{|c|}{ MUC2 mRNA } \\
\hline & $\mathrm{n}$ & Ratio of $\mathrm{C} / \mathrm{N}$ & P-value & $\mathrm{n}$ & Ratio of $\mathrm{C} / \mathrm{N}$ & P-value & $\mathrm{n}$ & Ratio of $\mathrm{C} / \mathrm{N}$ & P-value \\
\hline Total patients & 31 & & & 35 & & & 35 & & \\
\hline Clinical stage & & & 0.328 & & & $0.018^{\mathrm{a}}$ & & & 0.355 \\
\hline $\mathrm{I}+\mathrm{II}$ & 17 & $1.0 \pm 0.1$ & & 21 & $3.7 \pm 0.6$ & & 20 & $1.0 \pm 0.4$ & \\
\hline $\mathrm{III}+\mathrm{IV}$ & 14 & $1.3 \pm 0.2$ & & 14 & $1.0 \pm 0.3$ & & 15 & $2.4 \pm 1.2$ & \\
\hline LN metastasis & & & 0.135 & & & 0.043 & & & 0.692 \\
\hline Yes & 12 & $1.5 \pm 0.1$ & & 11 & $3.3 \pm 0.5$ & & 13 & $1.5 \pm 0.7$ & \\
\hline No & 19 & $1.0 \pm 0.1$ & & 24 & $1.0 \pm 0.3$ & & 22 & $1.0 \pm 0.4$ & \\
\hline Differentiation & & & 0.605 & & & $0.049^{\mathrm{a}}$ & & & 0.519 \\
\hline Well & 9 & $1.1 \pm 0.1$ & & 8 & $1.0 \pm 0.3$ & & 10 & $1.0 \pm 0.5$ & \\
\hline Moderate or Poor & 22 & $1.0 \pm 0.1$ & & 27 & $4.9 \pm 0.9$ & & 25 & $2.0 \pm 0.9$ & \\
\hline
\end{tabular}

${ }^{\text {a}}$ Data showed heterogeneity of variance. Student's $t$-tests and Mann-Whitney U tests were used to determine the significance of differences between groups. LN, lymph node; $\mathrm{C} / \mathrm{N}$, cancerous tissue/non-cancerous tissue; IRE1, inositol-requiring enzyme 1; MUC2, mucin 2. The data are presented as the mean \pm standard deviation.

tissues, compared with the adjacent non-cancerous tissues. Therefore, the results suggest that the IRE1 $\alpha$-XBP1 signaling pathway does not have an important role in the progression of CRC.

Colon epithelial cells also express IRE1 $\beta$, an analog of the ubiquitous IRE1 $\alpha$, which has differing functions to IRE1 $\beta$ with regard to cell survival and apoptosis $(29-32,47)$. IRE1 $\beta$ is inefficient at cleaving XBP1 mRNA and directly interacts with unfolded proteins in the ER by association with glucose-regulated protein 78 , which is crucial regulator of ER stress (26). Therefore, the IRE1 $\beta$ expression levels in patients with CRC were also analyzed. The present study demonstrated that the mRNA and protein expression levels of IRE1 $\beta$ were significantly decreased in CRC tissues. It is possible that the decreased expression levels reflect the transition of normal epithelial cells to cancerous cells. The IHC results revealed positive IRE1 $\beta$ staining in all epithelial cells, suggesting that IRE1 $\beta$ affects not only goblet cells, but also epithelial cells. A previous study reported that IRE1 $\beta$ regulates lipid absorption by mediating the transcription of 
Table V. Association between the immunohistochemical staining of IRE1 $\beta$ and the clinical characteristics of patients with colorectal carcinoma $(n=35)$.

\begin{tabular}{lcccr}
\hline & & \multicolumn{2}{c}{ IRE1 $\beta$} \\
\cline { 3 - 5 } Variable & Patients, $\mathrm{L}$ & Low, $\mathrm{n}$ & High, $\mathrm{n}$ & P-value \\
\hline Clinical stage & & & & 0.001 \\
$\quad$ I+II & 21 & 2 & 12 & 0.009 \\
III+IV & 14 & 2 & 9 & 0.047 \\
Lymph node metastasis & 11 & 17 & 7 & \\
$\quad$ Yes & 24 & & & \\
No1 & 8 & 7 & 15 & \\
Pathologic differentiation & 27 & 12 & & \\
$\quad$ Well & & & & \\
Moderate or Poor & &
\end{tabular}

Differences were analyzed by $\chi^{2}$ test. IRE1, inositol-requiring enzyme 1.
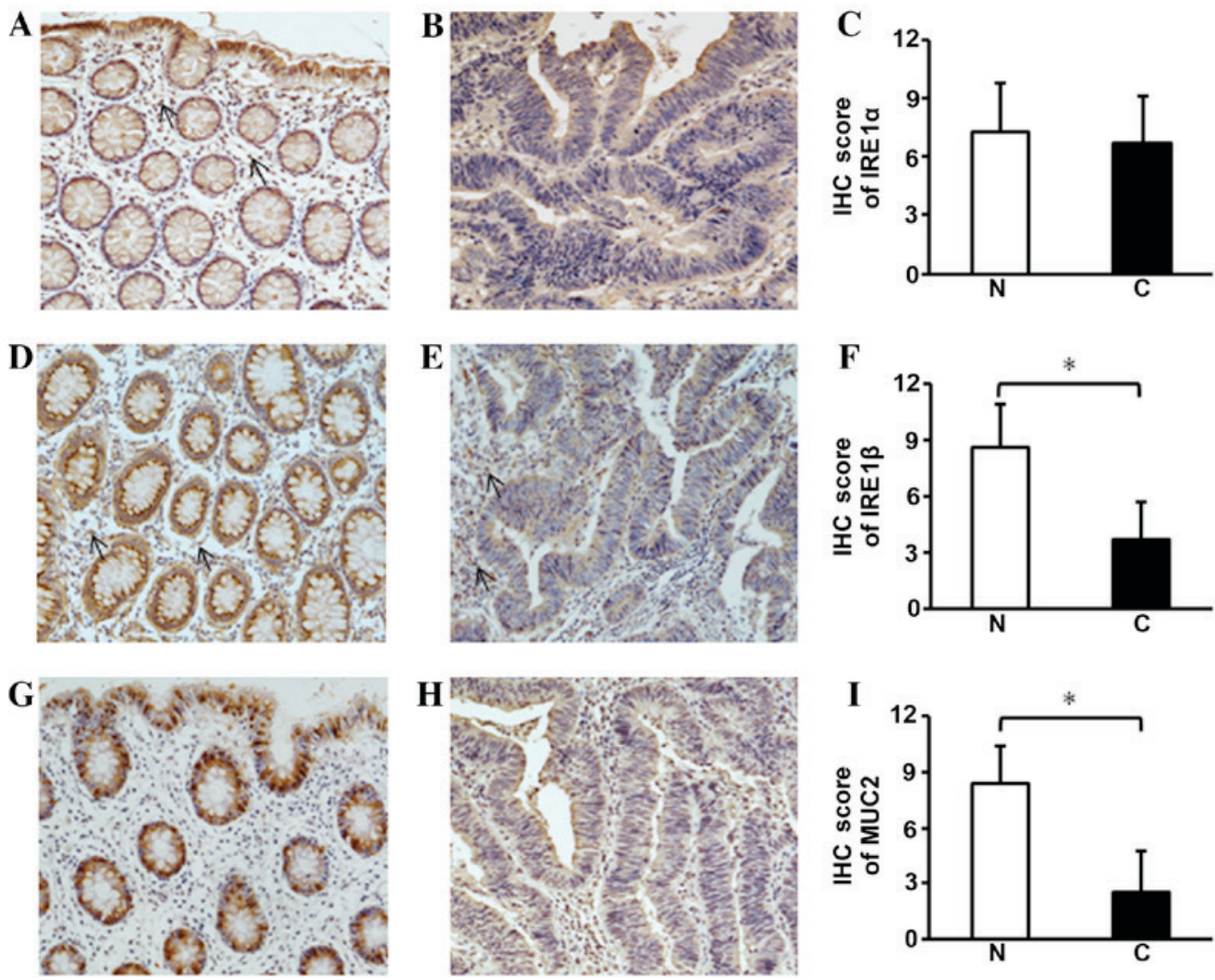

Figure 2. Immunohistochemistry of IRE1 $\alpha$, IRE1 $\beta$ and MUC2 in CRC tissues. (A) IRE1 $\alpha$ was expressed in the cytoplasm of epithelial cells in the crypts surface of non-cancerous tissues. In the submucosa unidentified cells were observed to have weakly positive staining (arrow). (B and C) In CRC tissues there was a similar level of the IRE1 $\alpha$ protein; (D) IRE1 $\beta$ was observed in the cytoplasm above the nuclei of the non-cancerous colonic epithelial cells. (E and F) In the CRC tissues, the cytoplasmic staining for IRE1 $\beta$ was faint, suggesting the expression of IRE1 $\beta$ was decreased; in the submucosa of the non-cancerous tissues and cancerous tissues there were also unidentified cells with weakly positive staining (arrow). (G) The staining for MUC2 was intensely positive in the goblet cells of the non-cancerous colonic epithelium; (H and I) in the CRC tissues MUC2 staining was barely visible. Representative immunostaining for (A and B) IRE1 $\alpha$, (D and E) IRE1 $\beta$ and (G and H) MUC2 and the semi-quantification of (C) IRE1 $\alpha$, (F) IRE1 $\beta$ and (I) MUC2 for each tissue group. The data are presented as the mean \pm standard deviation $\left(\mathrm{n}=35\right.$ for all three groups). ${ }^{*} \mathrm{P}<0.05$, vs. the non-cancerous tissues. $\mathrm{N}$, noncancerous tissues; $\mathrm{C}$, cancerous tissues; IRE1, inositol-requiring enzyme 1; MUC2, mucin 2; CRC, colorectal cancer; IHC, immunohistochemistry.

microsomal triacylglycerol transfer protein expression in the colon epithelium (53). However, the association between the change in lipid absorption and the tumorigenesis of CRC requires further study for elucidation. It was hypothesized that decreased IRE1 $\beta$ expression levels may be associated with tumorigenesis, as IRE1 $\beta$ is a protective factor for colitis 

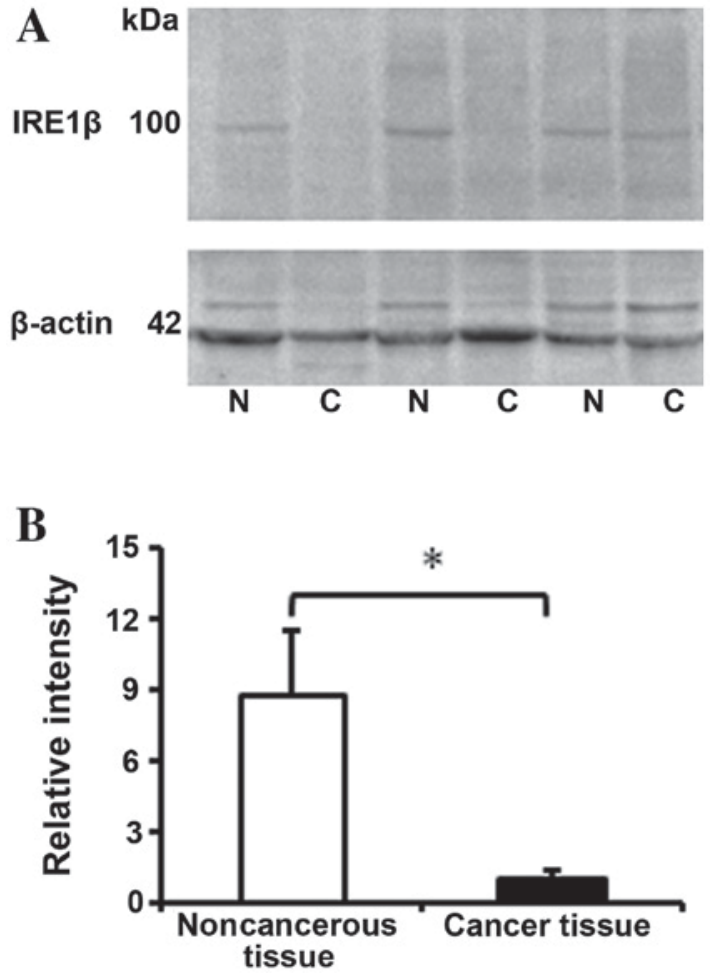

Figure 3. Western blot analysis of IRE1 $\beta$. (A) The representative immunoblotting images correspond to IRE1 $\beta$ protein expression levels in CRC tissues. (B) The protein expression levels of IRE1 $\beta$ were downregulated in CRC tissues, compared with non-cancerous tissues. The data are presented as the mean \pm standard deviation $(n=13) .{ }^{*} \mathrm{P}<0.05$, vs. the non-cancerous tissues. $\mathrm{N}$, noncancerous tissues; $\mathrm{C}$, cancerous tissues; IRE1, inositol-requiring enzyme $1 ;$ CRC, colorectal cancer.

and is involved in cell apoptosis $(26,32)$. Intestinal inflammation and cell apoptosis are putatively associated with occurrence of CRC (54). Analysis of the mRNA expression levels of IRE1 $\beta$ in tumor tissues revealed that higher IRE1 $\beta$ mRNA expression levels were significantly associated with poor tumor differentiation, lymph node metastasis and later TNM stage. The results suggest that IRE1 $\beta$ may be involved in the development of CRC. The results of the present study are concordant with the in vitro study conducted by Dai et al (55), who identified that the mRNA expression levels of IRE1 $\beta$ were high in undifferentiated Caco- 2 cells, and were correspondingly decreased following the differentiation of these cells (55).

Two previous studies have reported that IRE1 $\beta$ is an important regulator of MUC2 secretion $(28,33)$. In animal model studies, IRE1 $\beta^{-/^{-}}$mice were more susceptible to dextran sodium sulfate (DSS) -induced colitis, compared with wild type mice (26). The loss of intestinal mucin also increases the sensitivity of mice to DSS-induced colitis (56). IRE1 $\beta$ is essential for UPR in goblet cells, and MUC2 is its target protein $(27,33)$. In the current study, MUC2 expression levels were revealed to be decreased in colorectal adenocarcinomas. The results are concordant with previous studies, in which nonmucinous CRC tissues were negative for MUC2 expression $(57,58)$. This may be due to a decreased number of goblet cells in non-mucinous CRC tissues, as the expression of MUC2 was positively correlated with the mRNA expression levels of IRE1 $\beta$. However, it has previously been revealed that the methylation of the MUC2 promoter and the loss of functional tumor protein 53 may decrease MUC2 expression levels in CRC tissues $(59,60)$. Correlation analysis in the present study indicated that the expression levels of MUC2 were positively associated with the mRNA expression levels of IRE1 $\beta$. IRE1 $\beta$ and MUC2 act as protective factors to maintain the intestinal physiological homeostasis, and the suppression of the two proteins may be associated with the tumorigenesis of CRC.

In conclusion, the results of the current study revealed that the decreased expression levels of IRE1 $\beta$ in CRC tissues were associated with clinical features of patients with CRC. IRE1 $\beta$ gene expression levels were positively correlated with those of MUC2, indicating that IRE1 $\beta$ and MUC2 may be involved in the tumorigenesis of CRC. The association of IRE1 $\beta$ and MUC2, as well as the significance of IRE1 $\beta$ in $\mathrm{CRC}$, require further studies in order to identify novel therapeutic targets for this type of cancer.

\section{Acknowledgements}

The authors would like to thank Dr Yonggan Fan, Dr Xianli Liu and Dr Wenchao Zhao for their help with patient recruitment and pathological consultation in the present study. This study was supported by a grant (grant no. 81370487 to Q.Gao) from The National Natural Science Foundation of China.

\section{References}

1. Fleming M, Ravula S, Tatishchev SF and Wang HL: Colorectal carcinoma: Pathologic aspects. J Gastrointest Oncol 3: 153-173, 2012

2. Zhao P, Dai M, Chen W and Li N: Cancer trends in China. Jpn J Clin Oncol 40: 281-285, 2010.

3. Li L and Ma BB: Colorectal cancer in Chinese patients: Current and emerging treatment options. Onco Targets Ther 7: 1817-1828, 2014

4. Dai Z, Zheng RS, Zou XN, Zhang SW, Zeng HM, Li N and Chen WQ: Analysis and prediction of colorectal cancer incidence trend in China. Zhonghua Yu Fang Yi Xue Za Zhi 46: 598-603, 2012 (In Chinese).

5. Stintzing S: Management of colorectal cancer. F1000Prime Rep 6: 108, 2014.

6. Kim ER and Kim YH: Clinical application of genetics in management of colorectal cancer. Intest Res 12: 184-193, 2014.

7. SEER Stat Fact Sheets: Colon and Rectum Cancer), National Cancer Institute, Bethesda, MD, https://seer.cancer. gov/statfacts/html/colorect.html. September 1, 2015.

8. Manié SN, Lebeau J and Chevet E: Cellular mechanisms of endoplasmic reticulum stress signaling in health and disease. 3. Orchestrating the unfolded protein response in oncogenesis: An update. Am J Physiol Cell Physiol 307: C901-C907, 2014

9. Dicks N, Gutierrez K, Michalak M, Bordignon V and Agellon LB: Endoplasmic reticulum stress, genome damage, and cancer. Front Oncol 5: 11, 2015.

10. Parmar VM and Schröder M: Sensing endoplasmic reticulum stress. Adv Exp Med Biol 738: 153-168, 2012.

11. Gardner BM, Pincus D, Gotthardt K, Gallagher CM and Walter P: Endoplasmic reticulum stress sensing in the unfolded protein response. Cold Spring Harb Perspect Biol 5: a013169, 2013.

12. Gao Q, Esworthy RS, Kim BW, Synold TW, Smith DD and Chu FF: Atherogenic diets exacerbate colitis in mice deficient in glutathione peroxidase. Inflamm Bowel Dis 16: 2043-2054, 2010.

13. McMillan DR, Gething MJ and Sambrook J: The cellular response to unfolded proteins: Intercompartmental signaling. Curr Opin Biotechnol 5: 540-545, 1994. 
14. Papandreou I, Denko NC, Olson M, Van Melckebeke H, Lust S, Tam A, Solow-Cordero DE, Bouley DM, Offner F, Niwa $M$ and Koong AC: Identification of an Irelalpha endonuclease specific inhibitor with cytotoxic activity against human multiple myeloma. Blood 117: 1311-1314, 2011.

15. Greenman C, Stephens P, Smith R, Dalgliesh GL, Hunter C, Bignell G, Davies H, Teague J, Butler A, Stevens C, et al: Patterns of somatic mutation in human cancer genomes. Nature 446: 153-158, 2007.

16. Nakamura D, Tsuru A, Ikegami K, Imagawa Y, Fujimoto N and Kohno K: Mammalian ER stress sensor IRE1 $\beta$ specifically down-regulates the synthesis of secretory pathway proteins FEBS Lett 585: 133-138, 2011.

17. Koong AC, Chauhan V and Romero-Ramirez L: Targeting XBP-1 as a novel anti-cancer strategy. Cancer Biol Ther 5: 756-759, 2006

18. Yoshida H, Oku M, Suzuki M and Mori K: pXBP1(U) encoded in XBP1 pre-mRNA negatively regulates unfolded protein response activator $\mathrm{pXBP}(\mathrm{S})$ in mammalian ER stress response. J Cell Biol 172: 565-575, 2006.

19. Fujimoto T, Onda M, Nagai H, Nagahata T, Ogawa K and Emi M: Upregulation and overexpression of human X-box binding protein 1 ( $\mathrm{hXBP}-1)$ gene in primary breast cancers Breast Cancer 10: 301-306, 2003.

20. Shuda M, Kondoh N, Imazeki N, Tanaka K, Okada T, Mori K, Hada A, Arai M, Wakatsuki T, Matsubara O, et al: Activation of the ATF6, XBP1 and grp78 genes in human hepatocellular carcinoma: A possible involvement of the ER stress pathway in hepatocarcinogenesis. J Hepatol 38: 605-614, 2003.

21. Fujimoto T, Yoshimatsu K, Watanabe K, Yokomizo H, Otani T, Matsumoto A, Osawa G, Onda M and Ogawa K: Overexpression of human X-box binding protein 1 (XBP-1) in colorectal adenomas and adenocarcinomas. Anticancer Res 27: 127-131, 2007.

22. Takahashi S, Suzuki S, Inaguma S, Ikeda Y, Cho YM, Nishiyama N, Fujita T, Inoue T, Hioki T, Sugimura Y, et al: Down-regulation of human X-box binding protein 1 (hXBP-1) expression correlates with tumor progression in human prostate cancers. Prostate 50: 154-161, 2002.

23. Chen Y and Brandizzi F: IRE1: ER stress sensor and cell fate executor. Trends Cell Biol 23: 547-555, 2013.

24. Coelho DS and Domingos PM: Physiological roles of regulated Irel dependent decay. Front Genet 5: 76, 2014

25. Welihinda AA, Tirasophon W and Kaufman RJ: The cellular response to protein misfolding in the endoplasmic reticulum. Gene Expr 7: 293-300, 1999.

26. Bertolotti A, Wang X, Novoa I, Jungreis R, Schlessinger K, Cho JH, West $\mathrm{AB}$ and Ron D: Increased sensitivity to dextran sodium sulfate colitis in IRE1beta-deficient mice. J Clin Invest 107: 585-593, 2001

27. Martino MB, Jones L, Brighton B, Ehre C, Abdulah L, Davis CW, Ron D, O'Neal WK and Ribeiro CM: The ER stress transducer IRE1 $\beta$ is required for airway epithelial mucin production. Mucosal Immunol 6: 639-654, 2013.

28. Zhang HS, Chen Y, Fan L, Xi QL, Wu GH, Li XX, Yuan TL, He SQ, Yu Y, Shao ML, et al: The Endoplasmic Reticulum Stress Sensor IRE1 $\alpha$ in Intestinal Epithelial Cells Is Essential for Protecting against Colitis. J Biol Chem 290: 15327-15336, 2015.

29. Lin JH, Li H, Yasumura D, Cohen HR, Zhang C, Panning B, Shokat KM, Lavail MM and Walter P: IRE1 signaling affects cell fate during the unfolded protein response. Science 318: 944-949, 2007.

30. Hetz C: The unfolded protein response: Controlling cell fate decisions under ER stress and beyond. Nat Rev Mol Cell Biol 13: 89-1026, 2012

31. Hetz C and Glimcher LH: Fine-tuning of the unfolded protein response: Assembling the IRE1alpha interactome. Mol Cell 35: 551-561, 2009

32. Iwawaki T, Hosoda A, Okuda T, Kamigori Y, Nomura-Furuwatari C, Kimata Y, Tsuru A and Kohno K: Translational control by the ER transmembrane kinase/ribonuclease IRE1 under ER stress. Nat Cell Biol 3: 158-164, 2001.

33. Tsuru A, Fujimoto N, Takahashi S, Saito M, Nakamura D, Iwano M, Iwawaki T, Kadokura H, Ron D and Kohno K: Negative feedback by IRE1 $\beta$ optimizes mucin production in goblet cells. Proc Natl Acad Sci USA 110: 2864-2869, 2013

34. Johansson ME and Hansson GC: Mucus and the goblet cell. Dig Dis 31: 305-309, 2013.

35. Johansson ME, Phillipson M, Petersson J, Velcich A, Holm L and Hansson GC: The inner of the two Muc2 mucin-dependent mucus layers in colon is devoid of bacteria. Proc Natl Acad Sci USA 105: 15064-15069, 2008.
36. Kawashima H: Roles of the gel-forming MUC2 mucin and its $\mathrm{O}$-glycosylation in the protection against colitis and colorectal cancer. Biol Pharm Bull 35: 1637-1641, 2012.

37. Van der Sluis M, De Koning BA, De Bruijn AC, Velcich A, Meijerink JP, Van Goudoever JB, Büller HA, Dekker J, Van Seuningen I, Renes IB and Einerhand AW: Muc2-deficient mice spontaneously develop colitis, indicating that MUC2 is critical for colonic protection. Gastroenterology 131: 117-129, 2006.

38. Velcich A, Yang W, Heyer J, Fragale A, Nicholas C, Viani S, Kucherlapati R, Lipkin M, Yang $\mathrm{K}$ and Augenlicht L: Colorectal cancer in mice genetically deficient in the mucin Muc2. Science 295: 1726-1729, 2002

39. Imai Y, Yamagishi H, Fukuda K, Ono Y, Inoue T and Ueda Y: Differential mucin phenotypes and their significance in a variation of colorectal carcinoma. World J Gastroenterol 19: 3957-3968, 2013.

40. Debunne H and Ceelen W: Mucinous differentiation in colorectal cancer: Molecular, histological and clinical aspects. Acta Chir Belg 113: 385-390, 2013.

41. Edge SB and Compton CC: The American Joint Committee on Cancer: The 7th edition of the AJCC cancer staging manual and the future of TNM. Ann Surg Oncol 17: 1471-1474, 2010.

42. Untergasser A, Cutcutache I, Koressaar T, Ye J, Faircloth BC, Remm M and Rozen SG: Primer3-new capabilities and interfaces. Nucleic Acids Res 40: e115, 2012.

43. Xu FX, Su YL, Zhang H, Kong JY, Yu H and Qian BY: Prognostic implications for high expression of MiR-25 in lung adenocarcinomas of female non-smokers. Asian Pac J Cancer Prev 15: 1197-1203, 2014.

44. Gao Q, Meijer MJ, Kubben FJ, Sier CF, Kruidenier L, van Duijn W, van den Berg M, van Hogezand RA, Lamers CB and Verspaget HW: Expression of matrix metalloproteinases-2 and -9 in intestinal tissue of patients with inflammatory bowel diseases. Dig Liver Dis 37: 584-592, 2005.

45. Liu C, Huang Z, Jiang H and Shi F: The sirtuin 3 expression profile is associated with pathological and clinical outcomes in colon cancer patients. Biomed Res Int 2014: 871263, 2014.

46. Liu S, Zheng R, Zhang M, Zhang S, Sun X and Chen W: Incidence and mortality of colorectal cancer in China, 2011. Chin J Cancer Res 27: 22-28, 2015.

47. Imagawa Y, Hosoda A, Sasaka S, Tsuru A and Kohno K: RNase domains determine the functional difference between IRE1alpha and IRE1beta. FEBS Lett 582: 656-660, 2008.

48. Piemonte M: [TNM - classification of malignant tumors (VI edition - 2002). Innovations in the classification of head and neck neoplasms]. Acta Otorhinolaryngol Ital 23: 132-135, 2003 (In Italian).

49. Wei Q, Huang X, Fu B, Liu J, Zhong L, Yang Q and Zhao T: IMP3 expression in biopsy specimens of colorectal cancer predicts lymph node metastasis and TNM stage. Int J Clin Exp Pathol 8: 11024-3213, 2015.

50. Kesari MV, Gaopande VL, Joshi AR, Babanagare SV, Gogate BP and Khadilkar AV: Immunohistochemical study of MUC1, MUC2 and MUC5AC in colorectal carcinoma and review of literature. Indian J Gastroenterol 34: 63-67, 2015.

51. Walsh MD, Clendenning M, Williamson E, Pearson SA, Walters RJ, Nagler B, Packenas D, Win AK, Hopper JL, Jenkins MA, et al: Expression of MUC2, MUC5AC, MUC5B, and MUC6 mucins in colorectal cancers and their association with the $\mathrm{CpG}$ island methylator phenotype. Mod Pathol 26: 1642-1656, 2013.

52. Okudaira K, Kakar S, Cun L, Choi E, Wu Decamillis R, Miura S, Sleisenger MH, Kim YS and Deng G: MUC2 gene promoter methylation in mucinous and non-mucinous colorectal cancer tissues. Int J Oncol 36: 765-775, 2010.

53. Iqbal J, Dai K, Seimon T, Jungreis R, Oyadomari M, Kuriakose G, Ron D, Tabas I and Hussain MM: IRE1beta inhibits chylomicron production by selectively degrading MTP mRNA. Cell Metab 7: 445-455, 2008.

54. Terzić J, Grivennikov S, Karin E and Karin M: Inflammation and colon cancer. Gastroenterology 138: 2101-2114. e5, 2010.

55. Dai K, Khatun I and Hussain MM: NR2F1 and IRE1beta suppress microsomal triglyceride transfer protein expression and lipoprotein assembly in undifferentiated intestinal epithelial cells. Arterioscler Thromb Vasc Biol 30: 568-574, 2010.

56. Heazlewood CK, Cook MC, Eri R, Price GR, Tauro SB, Taupin D, Thornton DJ, Png CW, Crockford TL, Cornall RJ, et al: Aberrant mucin assembly in mice causes endoplasmic reticulum stress and spontaneous inflammation resembling ulcerative colitis. PLoS Med 5: e54, 2008. 
57. Manne U, Weiss HL and Grizzle WE: Racial differences in the prognostic usefulness of MUC1 and MUC2 in colorectal adenocarcinomas. Clin Cancer Res 6: 4017-4025, 2000.

58. Matsuda K, Masaki T, Watanabe T, Kitayama J, Nagawa H, Muto T and Ajioka Y: Clinical significance of MUC1 and MUC2 mucin and p53 protein expression in colorectal carcinoma. Jpn J Clin Oncol 30: 89-94, 2000.
59. Gratchev A, Siedow A, Bumke-Vogt C, Hummel M, Foss HD, Hanski ML, Kobalz U, Mann B, Lammert H, Mansmann U, et al: Regulation of the intestinal mucin MUC2 gene expression in vivo: Evidence for the role of promoter methylation. Cancer Lett 168: 71-80, 2001.

60. Ookawa K, Kudo T, Aizawa S, Saito H and Tsuchida S: Transcriptional activation of the MUC2 gene by p53. J Biol Chem 277: 48270-48275, 2002. 